\title{
LA LECTURA DE LIBORIO HIERRO Y FRANCISCO LAPORTA DE LOS CLÁSICOS: EL VALOR DE LA HISTORIA
}

\author{
Julián Sauquillo \\ Universidad Autónoma de Madrid
}

\begin{abstract}
ué diálogo sostienen Liborio HIERRO y Francisco LAPORTA con los clásicos? ¿Se trata de una relación complaciente o de un duelo? Ninguno de nuestros dos colegas y amigos se enfrenta a los clásicos. Sería impropio de dos grandes lectores contrariar a quienes siguen alumbrando nuestro incierto camino. Se confrontan, más bien, con quienes suponemos clásicos del pensamiento por haber superado el paso del tiempo. Como no tenemos ni idea de qué va a pasar en el futuro, solo me atrevo a decir que, muy probablemente, ellos también lleguen a ser dos clásicos de la filosofía del lenguaje aplicada al derecho y a los derechos humanos. Son ya dos maestros en sentido neto. De hecho, me centraré en sus dos últimas obras fundamentales a las que auguro muchos lectores y gran reconocimiento. Si les sitúo frente a los clásicos es porque ellos, bien seguro, no eludieron las relaciones especulares que tenemos con cierta escritura que se inscribe en el pasado. Saben que la historia que los clásicos políticos encierran es maestra de la vida. Sin embargo, creo que se han puesto frente a los clásicos de formas diferentes y en un grado que va del convencimiento y el entusiasmo al olvido o al desengaño. A veces para volver a ilusionarse.
\end{abstract}

Siempre me intrigó que Liborio HIERRO comenzara su jornada laboral en la universidad leyendo, constante y diariamente, a algún clásico, según oí, una vez, a Alfonso Ruiz Miguel. De hecho, sé que se ocupó mucho tiempo de Las Leyes de Platón. También recuerdo que Francisco LAPORTA, a la vuelta de uno de sus viajes a Oxford, señalara que los contemporáneos de la filosofía analítica solían publicar una monografía sobre algún clásico del pensamiento que se convertía en obra de referencia inmediatamente. Aunque me pareció entender que lo decía como ejemplo de deslinde metodológico entre la argumentación filosófica y el escudriñamiento historiográfico. Me consta que le encantan los clásicos y su visión del pasado, tan útil para entender el presente. Pero, a veces, LAPORTA fue tajante a la hora de subtitular su obra con «una visión actual». Me chocó tal pulcritud respecto de la historia en su trabajo. Así es porque buscaba La Constitución alemana con perentoriedad un día y se trata de un clásico complejo. Es debido a quien ADORNo llamó «Hegel el oscuro». Su lectura suponía un «tour de force» para un filósofo analítico.

Como LAPORTA también se interesó juvenilmente en el «estructuralismo», me permito decir que nuestro colega suele situarse en el corte sincrónico y evitar el diacróni- 
co. Quizá porque somos historia y nadie puede trascender el presente para desentrañar con certeza el pasado. Pretender adentrarse en el túnel del tiempo con billete de regreso es tan difícil como saltar por encima de nuestra propia sombra. Si apareciera un heleno hoy, y entendiéramos su griego arcaico, tumbaría toneladas de anaqueles de historiografía antigua. Así que el deslinde de LAPORTA parece muy sensato. No podemos hacer sino «retroproyecciones» de nuestro presente en el pasado. Cierto, pero LAPORTA es heredero de Dracón de Tesalia. Así que no creo que a LAPORTA le dé igual la historia, como uno de nuestros más queridos maestros señalaba, en cambio, concluyentemente. Apuntaré que su «visión actual» del imperio de la ley tiene que tomar distancia de modelos de pensar pasados como si fueran depósitos de palabras muertas. Palabras fenecidas que se niegan, no obstante, a permanecer mudas hoy. Algo diré en este sentido.

El caso de Liborio HIERRO es, por el contrario, meridiano en favor de la historia. La historia no le es refractaria. Casi partió del análisis histórico - tras sus Textos básicos sobre Derechos Humanos (1973) con Gregorio PECES-BARBA- para internarse, después, en el realismo jurídico y la filosofía analítica. ¿Qué relación guarda entonces con los clásicos? Las referencias a Platón, ARistóteles, Tomás de AQuino, Locke, Hume, Bentham, Tocqueville, Durkheim, Costa, MarX y Engels, Veblen o al propio RUSSELL enriquecen pero no forman el argumento central ni sobre los realistas escandinavos ni de su teoría del derecho. No se adentraba en el pasado y era manifiestamente actual. Sin embargo, vuelve, ahora, a la historia de los derechos humanos con un impulso mayoritario y muy sugestivo en su último libro. Mientras que la reflexión de LAPORTA es un arsenal formidable de argumentos actuales y puede resultar divertido buscarle su particular historia, como pequeña diablura, a HIERRO se le pueden hacer sesudas preguntas directamente historiográficas. Se apoya también, abiertamente, en el pasado. Alguna le haré.

Me atrevo a suponer que de las catorce razones que Italo CALviNO da para leer a los clásicos, HIERRO suscribiría la séptima («Los clásicos son esos libros que nos llegan trayendo impresa la huella de las lecturas que han precedido a la nuestra, y tras de sí la huella que han dejado en la cultura o en las culturas que han atravesado (o más sencillamente, en el lenguaje o en las costumbres)»); mientras que LAPORTA atiende, más bien, a la decimocuarta ( «Es clásico lo que persiste como ruido de fondo incluso allí donde la actualidad más incompatible se impone»). En todo caso, me imagino entrando con ellos a mi escritorio, quitándonos la ropa cotidiana para sustraernos de una jornada ordinaria, vistiéndonos con paños reales y curiales, para entrar juntos, de esta guisa, en las antiguas cortes de los nobles hombres y preguntarles a los clásicos por la razón de sus acciones. MAQUIAVELO sentía que había nacido para ellos, que formaban su alimento propio y que, por cuatro horas diarias, podía alimentarse amorosamente de ellos (Epístola a Francesco Vettori, Roma, 23 de noviembre de 1513). ¿Y nosotros? ¿Qué tiempo dedicamos a los clásicos?

El argumento de LIBORIO en Los derechos humanos. Una concepción de la justicia (2016) sostiene una tesis fuerte: es errónea la concepción histórica de los derechos humanos que supone tres o cuatro oleadas de sucesivos derechos. Su exposición se basa en un relato histórico excelentemente documentado. Pero también en la prudencia o imprudencia de lo afirmado para la efectividad de las llamadas primera, segunda y ter- 
cera generación de derechos. No comparte dos afirmaciones de las que previene: que los derechos civiles sean universales y efectivos, al garantizarse por su reconocimiento jurídico, mientras que las generaciones posteriores sean derechos en sentido impropio al albur de ideales difíciles de alcanzar; y que la primera generación de derechos sea hueca y baldía, mientras no se reconozcan los derechos económicos, sociales y culturales a todos. Si la primera me parece improcedente, tengo dudas sobre si la segunda es equivocada o no. La inexistencia de una vida cómoda y decente para todos los que viven en sociedad acucia el interés por los derechos económicos, sociales y culturales, a la vez que agudiza el descrédito por los derechos civiles en su forma actual. Mujeres, pensionistas, pobres, inmigrantes, gente sin casa, desempleados reivindican mayor bienestar y cuotas mejores de participación. ¿No languidece una «ciudadanía formal» y despunta una «ciudadanía sustantiva»?

Por ello, me preguntaré, más bien, qué pudo pasar realmente en el origen de los derechos humanos, aunque su repetido progreso - no sin fuertes zozobras y retrocesos, subrayados por la brillante exposición histórica de LIBORIO- lo haya podido borrar. ¿Acaso no existe una corriente autoritaria subyacente bajo el tránsito del Antiguo Régimen a la Revolución francesa que emerge palmaria en la Restauración en vez de sucesivos cambios de tercio históricos más o menos diáfanos? ¿No solemos afirmar las luminosas y celebrables rupturas históricas demasiado en vez de las sombrías y enojosas continuidades? Marcel GAUCHET trata de elaborar una genealogía de los derechos humanos. Su método filosófico con perspectiva histórica debe mucho al análisis crítico que TOCQueviLLE realiza en La Democracia en América $(1835,1840)$ y El Antiguo Régimen y la Revolución (1855). El análisis de la revolución francesa, y sus carencias, aporta una desconfianza básica hacia los grandes cambios y transformaciones atribuidas habitualmente a la Revolución. Bajo las grandes trasformaciones revolucionarias, perdura una corriente autoritaria mucho más profunda que su efecto de superficie: el cambio de manos del poder de la monarquía y los nobles al tercer estado. Es indudable que hubo modificaciones de importancia: desaparecen las estructuras feudales, estamentales, y aparecen los individuos. Pero a un orden de dominación le sucede otro. Cambian las oligarquías: de los aristócratas y sus privilegios a los propietarios y sus beneficios. Entre la Monarquía, de una parte, y el Bonapartismo y la Restauración, de otra, permanece un continuo autoritario que abole las capacidades contestatarias. Se dio un repliegue de la Revolución sobre el RousSEAu práctico (trivial) que aconseja se ejerciten cosas fáciles y seguras para Polonia. Ponen los deberes por encima de los derechos, bajo el supuesto de que primero se cumplan aquellos y luego se arguyan estos. El contenido de la Revolución —en el argumento historiográfico de Marcel GAUCHET— había sido, poco a poco y definitivamente, mutilado.

Como somos hijos de ese sujeto maltrecho de la modernidad, los derechos humanos con su «capacidad volcánica» sufrirán —me parece— un letargo ilimitado —iniciado en sus orígenes- si solo son impulsados desde las cúspides administrativas y no lo son desde la sociedad civil. No habrá derechos humanos sin el impenitente ejercicio del «imperativo de la disidencia» — las «exigencias morales» del querido Javier MuGUERZA - frente a las maquinarias burocráticas que proclaman su existencia y promoción pero, frecuentemente, los agotan. El filósofo afronta —según PLATÓN en sus Cartas - peligros, entonces, en la vida política. Según SÉNECA, al filósofo solo le espera 
la combustión en la actividad política. ¿Acaso le cundió excesivo pesimismo al filósofo estoico?

En su día celebré públicamente la edición de El imperio de la ley una visión actual (2007) en una revista de gran difusión ${ }^{1}$. Me complació sobre manera que a su autor le gustase mi comentario. Una de las circunstancias afortunadas de las que ahora podemos congratularnos es que entre HIERRO y LAPORTA, casualmente, han completado la concepción de la teoría de la justicia. Para LAPORTA no era suficiente la racionalidad jurídico-formal del imperio de la ley. Era necesario el reconocimiento de derechos para todos los ciudadanos (Ronald Dworkin). Se limitaba, por el momento, a su comprensión como conjunto de reglas. La «concepción-derechos» y la «concepción-libro de reglas» son bien avenibles según demuestran en sus dos últimos libros. LAPORTA concebía su libro sobre el imperio de la ley como un primer paso, pues sin imperio de las reglas no caben ni concepto ideal de justicia ni catálogos constitucionales de derechos fundamentales. Su imperio de la ley era ideado como ingrediente necesario del ideal de justicia que nos indica cómo debiera ser el derecho. Contradice la preponderancia excesiva de la Constitución en todas las tareas normativas, casi excluyente de la legislación. Me llamaba la atención su aproximación a las críticas formuladas por Elías DíAZ a la exacerbación del Estado Constitucional de Derecho y la entronización del papel de los jueces. El imperio de la ley es un retorno a la reivindicación de la codificación como neocodificación frente a la exageración neoconstitucionalista. Su opción en favor del normativismo va a contracorriente. La ley y la Constitución se ven agitadas por un «flujo y reflujo de mareas» y estamos en un tiempo deseable de «pleamar de las normas». El legislador racional recuperaba terreno así sobre el «judicialismo» rampante. Las reglas de conducta y las reglas de competencia eran el cimiento de una oceanografía jurídica calmada. Encierra una propuesta plausible de cómo debe ser creado, interpretado y aplicado el derecho positivo. Se sitúa en el positivismo normativista, positivismo ético o ética del legalismo. Su apuesta clara por la literalidad de la ley guarda resonancia del MonTESQUIEU de «el juez como boca de la ley». La predecibilidad de las decisiones judiciales aparece como un caso muy importante del cálculo racional deseable que debemos poder hacer sobre las posibles acciones de todos los agentes sociales. Sin instituciones sociales, como el derecho, construidas a partir de reglas, no cabe autonomía social. Según el argumento excelente de LAPORTA, sin predecibilidad de las acciones sociales a través de reglas no hay conocimiento del contexto social de actuación y, por tanto, la autonomía personal es imposible. Su método aparta rigurosamente las mediaciones psicológicas del comportamiento - a las ciencias sociales y humanas les compete tal estudio explicativo— para centrarse en el ámbito normativo de la previsibilidad. Ni su teoría del lenguaje ni su teoría de la acción son creacionistas. El rol (tanto de jueces como de ciudadanos) se justifica por los estándares de comportamiento, dados por la adhesión a reglas e independientes de los individuos. Sin embargo, las reglas pueden ser también un «Manual de Especuladores». LAPORTA deshace esta paradoja de la racionalidad de las normas al señalar cómo la justificación de una norma se da en el juicio moral universal. Un juicio que no aparece en el especulador legal o en 72-77.

1 J. SAuquillo, «La pleamar de las leyes», Claves de Razón Práctica, núm. 184, julio-agosto de 2008, 
el infractor que saca partido de un incumplimiento muy calculado en un contrario contexto general de obediencia a las normas.

Su sobresaliente conocimiento de la tradición soberanista —BODINO, HoBBES, Austin, SchmitT...- es un disolvente eficaz de los intentos de quiebra constitucional aducida, consciente o inconscientemente, por quienes revocan nuestra Transición política. Pero las materializaciones sociales de un «mundo sin reglas» abarcan también a la justicia del caso concreto o al escepticismo ante las reglas del Critical Legal Studies Movement, compatibles con un sistema democrático. Joseph RAZ y Friedrich SCHAUER le acompañaban en esta empresa. El mayor mérito de LAPORTA en su último libro es aclarar la confusión en que incurrimos cuando hablamos de discrecionalidad y creación judicial. Es firme en aclarar que el legislador, y no el intérprete judicial, es quien crea la ley. Su contundencia contra una concepción pragmática y «adanista» de la ley no deja dudas. La necesaria indeterminación y vaguedad del lenguaje jurídico, así como el conocimiento de los problemas de interpretación jurídica (sintácticos, lógicos, semánticos y pragmáticos) de la norma, en un sistema formado por otros textos («cotexto»), no le conduce a concebir la interpretación como un acto arbitrario. Concluía en una teoría y metodología de la interpretación como teoría de la argumentación. El caos normativo y la imprevisibilidad normativa acuciaban la oportunidad de la reflexión de LAPORTA.

Su «visión actual» convoca a muchos clásicos - Platón, ARISTÓteles, Pico DE la Mirandola, Rousseau, Kant, Bentham, Bryce, Weber, O. W. Holmes, Kelsen, RAWLS- pero con una llamativa predilección por sus contemporáneos y un cosmopolitismo notable. No me cabe duda de que poco podemos saber del pasado espiritual más que un manojo de datos fiables. Es más previsible el presente y, por su puesto, más afrontable en sus problemas. Sin embargo, una «visión actual» no puede evitar inscribirse en el tiempo y poseer un trasfondo histórico. Creo que LAPORTA encarna una concepción institucional y reformista que perdura, al menos, desde los inicios de la sociedad contemporánea. Es inevitable pensar en la dramática historia de España con sus debilidades organizativas en las instituciones. Pero reparemos en Inglaterra, donde Europa se miró favorablemente, por su fuerte tradición jurídica y política, centrada en el Parlamento. Bentham era un activista de la codificación. Toda neocodificación se inscribe en una historia de avances codificadores que refleja la lucha de la privilegiada casta de técnicos jurídicos — abogados, jueces-, aliados a oligarquías y cacicatos, frente a leales reformistas que desean acercar el conocimiento del derecho a todos los concernidos por las normas. Es la lucha de BENTHAM y, entre nosotros, de Costa por ensanchar el conocimiento jurídico. Este modelo de estudio y acción codificador es histórico — no es novedoso- y se levanta contra la imprevisibilidad de la reacción judicial amparada en costumbres pluriseculares. Emprende una batalla emocionante por el derecho escrito, claro, público y sistemático contra el despótico «iVuelva usted mañana!». LAPORTA se suma a estos leales reformadores contra el «Tyranus» arbitrario: el Nabucodonosor que ajusticiaba a sus súbditos por no adivinar sus sueños. La historiografía avanzada realizó una crítica sin paliativos de la supuesta encarnación del principio de publicidad de la ley, de su conocimiento extenso, que predominó en la tradición al analizar el liberalismo español del siglo XIX. Por ello, no dejo de ver en LAPORTA un espíritu histórico de reformador social. Un espíritu encantado de las 
posibilidades institucionales y algo decepcionado de las posibilidades sociales. Como Francisco MURILLO FERROL dijo que «no hay mejor forma de guardar un secreto en España que publicarlo en una revista científica», no tengo reparo en recordar algo que LAPORTA me dijo ante los irracionales resultados electorales de nuestros días: «iJulián... Tenemos que hacer algo con las mayorías!». Al principio me sentí halagado porque me hiciera participe de tan ambicioso proyecto. Pero pronto me vi sobrepasado por sus mayúsculas dimensiones. Algún adlátere de la Institución Libre de Enseñanza receló de una educación efectiva sobre los españoles. Deseó eficaces medidas políticas. Unas sensatas y otras disparatadas. Las educativas le parecieron extemporáneas. El negro panorama que LAPORTA le pintó a Josep M. VILAJOSANA, recientemente, me hace pensar que confía — de similar manera - en la fortaleza de las instituciones y no mucho en las reformas educativas en España. Observo mucho pesimismo en él. No es para menos, visto el panorama. Pero no sé si yerro con LAPORTA.

Una vez, Woody Allen —al que José Juan MORESO entregó el título de doctor «honoris causa» en la Pompeu Fabra- logró cenar con el gran Ingmar BERGMAN. No le cabía mayor satisfacción. Pero el judío americano se pasó, por lo visto, todo el tiempo expresando exclamaciones de admiración sin articular una sola oración. Así somos los tímidos y neuróticos. No nos relajamos ni con una banda de jazz. Paco y Liborio no son Ingmar y menos aún yo soy Woody. Pero tampoco he pasado de la onomatopeya con ellos. Lástima. Por poco, no hemos tenido más que comidas siempre amenizadas por un Elías DíAz irrefrenable. No fui asiduo a los cafés universitarios matutinos, que brindan una ocasión de sociabilidad. Así somos los tímidos. Podemos pasar, incluso, por soberbios. Tengo que mejorar esto. Nunca es tarde. ¡Va por ello! 